\title{
Evaluating the complementarity of the educational function in agriculture
}

\author{
Y. Ohe \\ Department of Food and Resource Economics, Chiba University, Japan
}

\begin{abstract}
Agriculture generates positive externalities to society in addition to food production without receiving compensation, which is called the multifunctionality of agriculture. The educational function of agriculture has not been fully examined despite the growing need for such services from urbanites. This paper focused on the educational function of agriculture by considering it as a joint product of farm production in terms of not only technical complementarity, but also of institutional complementarity, which includes institutional aspects such as food and rural culture. Data were obtained from the URL of the Farm Experience Net, launched in May 2003 and operated by the National Association for Promotion of Rural Youth Education in Japan. We employed statistical tests to clarify the features of the bodies or individual farmers who provide experience services. Findings and implications were as follows. Firstly, from the perspective of complementarity, we can classify that crop-wise or operation-wise experiences showed a strong connection with the technical complementarity of farms with seasonality, while food and rural cultural experiences had a strong connection with institutional complementarity with less seasonality. Secondly, non-governmental organizations, the quasipublic sector and farmers' groups played important roles in food and rural culture experience services. Thus, we should recognize the significance of both technical and institutional complementarity to extend the educational function of agriculture and the rural heritage. The combination of the two types of complementarity is effective in building a wide range of networks of those stakeholders who provide food and rural experience services while easing the constraints of seasonality.
\end{abstract}

Keywords: technical complementarity, institutional complementarity, educational function of agriculture, multifunctionality of agriculture, food and rural experience services, farm diversification, cultural diversity. 


\section{Introduction}

The educational function of agriculture is considered as a part of multifunctionality (Science Council of Japan [6]). Multifunctionality is a joint product with externality $(\mathrm{OECD},[2,3])$. Nevertheless, the process that generates multifunctionality has not been limited to cases of technical complementarity. Hagedorn [1] pointed out the existence of institutional complementarity as the institutional jointness in addition to technical complementarity. In the case of institutional complementarity, joint products are generated through the institutional process and factors. It is not uncommon in every country that the process of agricultural production is determined by institutional factors that have been formed historically for centuries. So, it is necessary to consider both technical and institutional complementarity to explore the issues of complementarity in multifunctionality in agriculture. Particularly, institutional complementarity plays an important role in generating multifunctionality in terms of social and cultural function. The educational function is such an example. Ohe [4] evaluated multifunctionality by focusing on the village function by incorporating the concept of institutional complementarity. Ohe [5] also evaluated the significance of educational dairy farms in connection with institutional complementarity. However, to my knowledge, as yet a full-fledged conceptual and empirical examination of the aspect of the connection between institutional complementarity and the educational function has not been conducted.

While farming experiences are connected with technical complementarity, experiences involving the food and agrarian heritage that include an educational function have a connection with institutional complementarity. To understand the educational function of agriculture properly, it is safe to say that we cannot overlook the role of institutional complementarity. Therefore, here we evaluate institutional complementarity from the agrarian cultural point of view. First, we make conceptual considerations of technical and institutional complementarity and then empirically examine their characteristics. Finally, we give policy recommendations on how to promote the educational function of agriculture in the future.

\section{Two concepts of complementarity}

The most common image of complementarity is the case of technical complementarity that represents the technically determined process of production of by-products that accompany the main products. The joint production of mutton and wool is a typical textbook example of technical complementarity. Traditionally, farm households, however, have been involved in not only agricultural production but also in producing processed food and crafts that richly reflect the distinctiveness of the local area. These products have been important elements that constitute local food culture and agrarian heritage. In this respect, these by-products are products of the institutional complementarity of food and agrarian heritage. Table 1 shows a comparison between technical and institutional complementarity. 
Table 1: $\quad$ Comparison of technical and institutional complementarity.

\begin{tabular}{ccc}
\hline Type & Process of generating complementarity & Experience services \\
\hline $\begin{array}{c}\text { Technical } \\
\text { complementarity }\end{array}$ & Technical process & Crop-wise services \\
$-\begin{array}{c}\text { Institutional } \\
\text { complementarity }\end{array}$ & $\begin{array}{c}\text { Institutional process } \\
\text { (rural life process) }\end{array}$ & Operation-wise services \\
\hline
\end{tabular}

Technical complementarity is basically determined by technical conditions and it is not manageable for farmers in the short/medium term. This fact, however, does not mean that technical complementarity is not variable. Agricultural production in reality, particularly crop farming, has apparent seasonality. For instance, rice planting and harvesting are the most common farming experiences and are naturally constrained by seasonality. In short, technical complementarity regarding the educational function involves seasonality in agricultural production.

Likewise, institutional factors, such as customs and culture that have been traditionally formed and constitute institutional complementarity, are not manageable in the short/medium term. These institutions, having traditionally been the foundation of agrarian life and production activities, are not selective, but are commonly applied to every member of the local community and are difficult to change. Thus, institutional complementarity enables us to have a wider scope in understanding the significance of local cultural diversity and farm diversification, which is not always the case with technical complementarity.

\section{Data and methodology}

Data were obtained from the URL of the Farm Experience Net, launched in May 2003 and operated by the National Association for Promotion of Rural Youth Education in Japan, a body under the administration of the Ministry of Agriculture, Forestry and Fisheries (MAFF). Data were collected from March to April in 2003 from the URL.

The merit of these data is that they have the widest coverage of farm experience services throughout the country, providing information on by whom, when, where and how experience services are provided. However, a demerit is that the data are devoid of factor input information necessary for the examination of factor input relationships such as production or the cost function. We employed statistical tests to clarify the features of the bodies or individual farmers who provide experience services. The sample size was 385 providers.

Experience services are classified into four types: crop-wise experiences, farming operation experiences, food culture and rural culture (Table 2). We identified the five most popular items for each type of experience service. Among crop-wise experiences, vegetables come first, followed by rice, dairy, fruit, and wheat/buckwheat. Operation-wise, the order of popularity was harvest, 
Table 2: $\quad$ Breakdown of experience services.

Crop-wise services: vegetables (191), rice (151), dairy (129), fruit (121), wheat/buckwheat (114), livestock (88), flowers (60)

Operation-wise services: harvest (250), planting (186), cultivation (174), taking care of livestock (131), milking (107), soil improvement (100)

Food culture services: making soba and udon noodles (109), rice cakes (107), dairy products (71), pickles (69), natto/tofu (56), fruit juice (38), mannan (36), miso (16), jam (16), sausage (11), bread/cookies (14), local cuisine (12), herb tea (3), others (104)

Rural culture services: harvest festival (105), straw craft (69), fire fly catching (48), morning bazaar (34), charcoal-making (18), collecting edible wild plants/picking mushrooms (17), bamboo craft (16), woodcraft (15), dyeing (15), pottery (11), vine craft (8), wreath-making (7), watching fish (2), others (135)

Source: the URL of the Farm Experience Net, owned by the National Association for Promotion of Rural Youth Education in March 2005. Total sample size is 385.

Note: Figure in the parenthesis means sample size.

Table 3: $\quad$ Partial correlation coefficients among experience services.

\begin{tabular}{ccccc}
\hline Services & Crop-wise & Operation-wise & Food culture & Rural culture \\
\hline Crop-wise & 1 & & & \\
Operation-wise & $0.4682 * * *$ & 1 & & \\
Food culture & $0.3824 * * *$ & $0.3433^{* * *}$ & 1 & \\
Rural culture & $0.2351^{* * *}$ & $0.2308^{* * *}$ & $0.6268 * * *$ & 1 \\
\hline
\end{tabular}

Source: Same as Table 2.

Note: *** $1 \%$ significance.

planting, cultivation, taking care of livestock, and milking. With regard to food culture experiences, experiences in preparing a variety of foods are provided, with buckwheat and udon noodles, rice cake, dairy products, pickles and soybean products (i.e. natto, fermented beans, and tofu-making) accounting for the five most popular. Of the wide range of activities under the topic of rural culture experiences, the five most often offered are harvest festivals, straw crafts, firefly catching, morning bazaars and charcoal making. Generally, the closer to the production process of agriculture, the more tightly the technical complementarity becomes. In this context, we can define that crop-wise and operation-wise experiences represent technical complementarity while food and rural culture experiences represent institutional complementarity because the agrarian heritage particularly works on these two culture experiences.

Regarding the statistical relationships shown in Table 3, the four types of services have statistically significant positive correlations with each other; this is especially evident between crop-wise and operation-wise services (partial coefficient 0.468 with $1 \%$ significance) and between food and rural culture 
services (0.627 with $1 \%$ significance). In the case of institutional complementarity, non-farm bodies can become providers, so we will empirically examine characteristics of each complementarity taking into account the differences in providers.

\section{Empirical examination on the complementarity of farm and rural experience services}

\subsection{Seasonality of experience services}

First, we examined the seasonality of the four types of services by focusing on the portion of providers in year-round operations. The result shows that there was a difference with statistical significance in crop-wise and operation-wise experiences as tabulated in Table 4 while there was no significant difference between food and rural culture experiences except for dairy products with $10 \%$ significance.

Among crop-wise services, the portion of providers with year-round operations was more than $60 \%$ of those providing flower and dairy farming experience services but was less than $50 \%$ of those offering fruit and vegetable experiences, reflecting the stronger production seasonality of the former (each $5 \%$ significance). In operation-wise services, that portion was more than $60 \%$ for dairy farming and livestock husbandry and less than $50 \%$ for crop farming, indicating stronger seasonality in the latter (each $1 \%$ significance).

To summarize, we statistically confirmed that dairy farming has weaker seasonality than crop farming whereas cultural experiences have negligible

Table 4: Percentage of year-round operations in crop-wise and operationwise services.

\begin{tabular}{|c|c|c|c|c|c|c|c|}
\hline \multicolumn{8}{|c|}{ Crop-wise experience services } \\
\hline Crop & Fruit & $\begin{array}{l}\text { Vege- } \\
\text { tables }\end{array}$ & Rice & $\begin{array}{c}\text { Wheat, } \\
\text { buckwheat }\end{array}$ & $\begin{array}{l}\text { Livestock } \\
\text { except dairy }\end{array}$ & $\begin{array}{l}\text { Dairy } \\
\text { farming }\end{array}$ & Flowers \\
\hline Sample size & 121 & 191 & 151 & 114 & 88 & 129 & 60 \\
\hline $\begin{array}{l}\% \text { year-round } \\
\text { operation }\end{array}$ & $42.2 * *$ & 48.7 & 55.0 & 57.0 & $59.1+$ & $63.6^{* * *}$ & $65.0 * *$ \\
\hline \multicolumn{8}{|c|}{ Operation-wise experience services } \\
\hline Operation & Harvest & $\begin{array}{l}\text { Culti- } \\
\text { vation }\end{array}$ & Planting & $\begin{array}{c}\text { Soil } \\
\text { improvement }\end{array}$ & $\begin{array}{c}\text { Rearing } \\
\text { management }\end{array}$ & Milking & - \\
\hline Sample size & 250 & 174 & 186 & 100 & 131 & 107 & - \\
\hline $\begin{array}{l}\% \text { year-round } \\
\text { operation }\end{array}$ & $45.6^{* * *}$ & $47.1+$ & 48.9 & $58.0+$ & $61.1 * * *$ & $64.5^{* * *}$ & - \\
\hline
\end{tabular}

Source: same as Table 2.

Note: Chi-square test was conducted; $* * *, * *, *,+$ indicate $1 \%, 5 \%, 10 \%, 20 \%$ (reference) significance, respectively. 
seasonality. Therefore, we can say that the combination of the two types, farm operation experiences with technical complementarity of tighter seasonality and culture experiences with weaker seasonality, will enable providers to offer yearround services.

\subsection{Provision of experience services}

Providers are classified into three types according to principles related to profitmaking behaviour: family farms and corporate farms aiming at profit maximization belong to the private sector (46.7\%); national and prefectural governments, municipalities and research and educational institutions are considered as the public sector (24.7\%); and intermediate bodies such as NGO, voluntary associations and agricultural cooperatives comprise the quasi-public sector $(28.6 \%)$. Thus, non-private providers account for more than half of the total providers of farm and rural experience services (53\%) (Figure 1). One reason is that the public sector promotes experience services proactively as a way of policy implementation, so we should consider this policy bias with regard to the relatively higher portion of public and quasi-public providers. These public and quasi-public providers offer their own experience services and play a role in organizing a network of providers from the private sector, such as farmers. Put differently, the public sector has two roles: as actual providers of services and as organizers of providers' networks. In this sense, it should be said that there is role sharing in educational services among sectors. Even services provided by the public sector are under the influence of the two types of complementarity.

Of crop-wise services, as shown in Table 5, fewer were offered in family farms (2.1 services), with more services being offered by the public sector (3.2 services). In contrast, regarding food and rural culture services, the quasi-public sector provided more services while the public sector provided fewer.

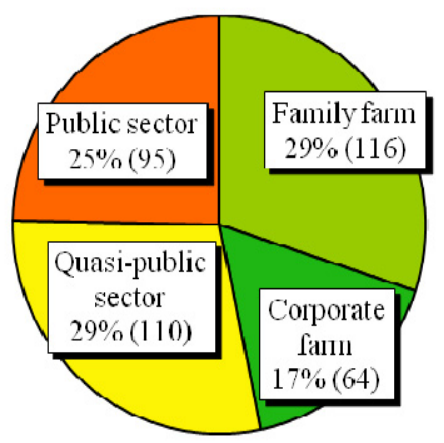

Note: sample size in parentheses

Figure 1: $\quad$ Proportion of providers. 
Table 5: $\quad$ Types of providers and experience service.

No. of offered services

\begin{tabular}{|c|c|c|c|c|c|c|c|c|c|c|c|c|c|}
\hline \multirow{3}{*}{ Items } & \multirow{3}{*}{$\begin{array}{c}\text { Sample } \\
\text { size }\end{array}$} & \multicolumn{12}{|c|}{ Provided services } \\
\hline & & \multicolumn{3}{|c|}{ Crop-wise } & \multicolumn{3}{|c|}{ Operation-wise } & \multicolumn{3}{|c|}{ Food culture } & \multicolumn{3}{|c|}{ Rural culture } \\
\hline & & Yes & No & test & Yes & No & test & Yes & No & test & Yes & No & test \\
\hline Family operation & 116 & 2.1 & 2.8 & $* * * \mathrm{~N}$ & 3.1 & 3.1 & n.s. & 1.8 & 1.7 & n.s. & 1.2 & 1.3 & n.s. \\
\hline Corporate operation & 64 & 2.3 & 2.1 & n.s. & 3.1 & 3.1 & n.s. & 1.7 & 1.7 & n.s. & 1.4 & 1.2 & n.s. \\
\hline Quasi-public sector* & 110 & 2.7 & 2.5 & n.s. & 3.2 & 3.1 & n.s. & 2.4 & 1.5 & $* * * \mathrm{~N}$ & 1.8 & 1.1 & $* * * \mathrm{E}$ \\
\hline Public sector** & 95 & 3.2 & 2.4 & $* * * \mathrm{~N}$ & 3.0 & 3.1 & n.s. & 1.0 & 2.0 & $* * * \mathrm{~N}$ & 0.7 & 1.5 & $* * * \mathrm{~N}$ \\
\hline Educational dairy farms & 93 & 1.9 & 2.8 & $* * * \mathrm{~N}$ & 3.0 & 3.1 & n.s. & 1.3 & 1.8 & $* * * \mathrm{~N}$ & 0.7 & 1.5 & $* * * \mathrm{~N}$ \\
\hline Green tourism farms & 24 & 3.0 & 2.5 & $+\mathrm{E}$ & 3.3 & 3.1 & n.s. & 2.6 & 1.7 & $* * \mathrm{E}$ & 2.1 & 1.2 & $* * * \mathrm{E}$ \\
\hline \multicolumn{14}{|c|}{$\begin{array}{l}\text { Source: Same as Table } 2 \text {. } \\
\text { Note 1: Test method: } \mathrm{t} \text { test, } \mathrm{E}=\text { equal variance, } \mathrm{N}=\text { not equal variance and } * * *, * *, *,+ \text { indicate } \\
1 \%, 5 \%, 10 \%, 20 \% \text { (reference), respectively and n.s. }=\text { not significant. }\end{array}$} \\
\hline
\end{tabular}

Operation-wise, there were no statistically significant differences among types of providers. Educational dairy farms provided fewer numbers of every type of service except operation-wise services (1\% significance). Dairy farming is constrained in that only a single product is produced. Green tourism, or Japanese rural tourism, farms offered more services among food and rural experiences than non-green tourism farms with statistical significance.

In short, the public sector has the advantage in crop-wise experiences, while such an advantage was shown for the quasi-public sector in food and rural experiences. Family farms and educational dairy farms offered fewer numbers of services due to a limited variety of products. In addition, it is considered that the differences in the scope of the providers' network in each sector accounted for some of these differences in types of services.

As to facilities, first, with respect to Internet accessibility, having a URL was associated with providing a greater number of services (Table 6). Likewise, email availability made a significant difference in the number of services offered. Therefore, it is safe to say that Internet availability is a necessary condition for the provision of educational services.

The number of offered services was significantly higher for food and rural culture experiences among those providers that charged for services, that targeted visitors nationwide, and that had a nearby accommodation facility than those whose services were offered free of charge, were limited to local visitors, and did not have accommodations nearby. These results indicate the value of attracting visitors from afar rather than limiting provision of services to the local population. Also overnight experience services combined with nearby accommodation facilities would be effective in promoting both experience services and rural tourism. Charging for services is undertaken to recover material costs used for experience services and opportunity cost for providers. Further, charging is an important step toward enhancing the recognition and value of these newly emerging services. 
Table 6: Characteristics of providers and experience services.

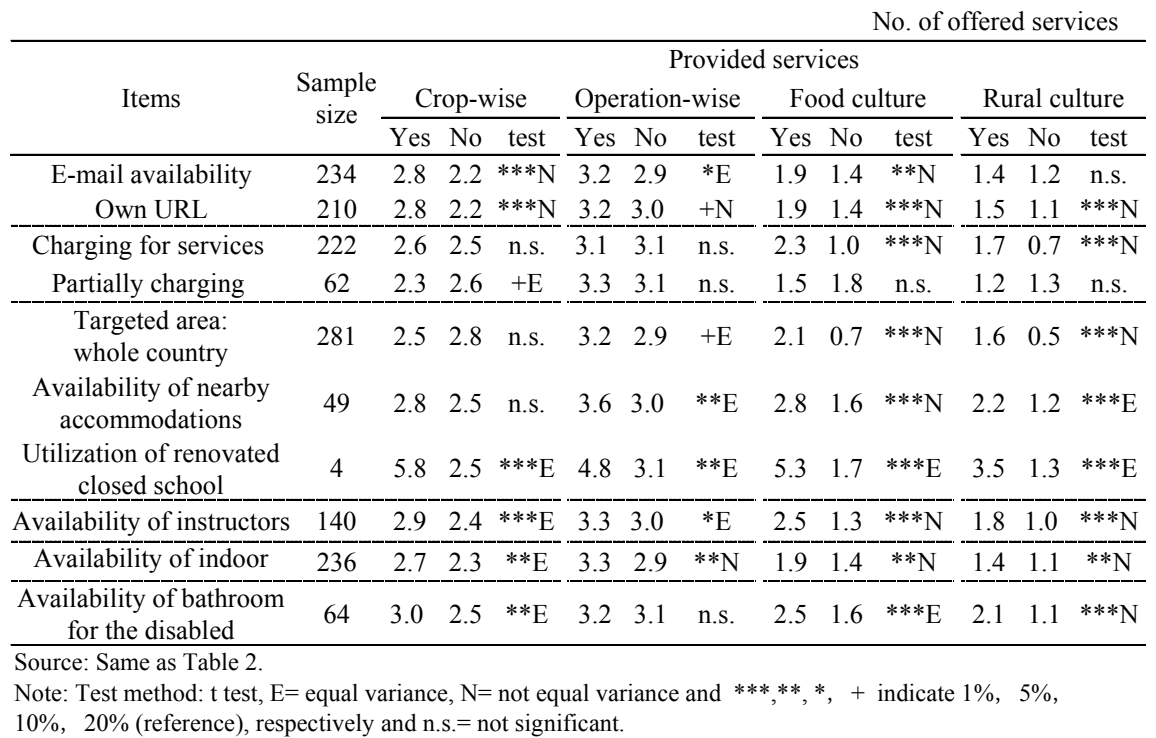

Looking at other aspects, utilization of renovated once-closed schools, providing instructors for guiding visitors in experiencing aspects of farm life, having indoor programs, and installation of a bathroom for the disabled all work positively on an increase in the number of services.

In summary, all of the conditions described above work positively to increase the number of provided experience services related to both technical and institutional complementarity. We cannot ignore the role of the public sector in experience services related to agricultural production with tighter technical complementarity because this sector plays a role in networking of providers. On the other hand, the quasi-public sector, such as NGO, plays an active role in culture experiences with institutional complementarity by charging for these services and accommodating visitors from a wide area. Thus, these results indicate that educational services go beyond the scope of technical and institutional complementarity. Since the quasi-public sector has an affinity for food and rural culture experience services, we should especially recognize and utilize this sector in promotion of culture-related educational services.

\section{Conclusions}

This paper focused on educational services related to agriculture as joint products of agriculture and investigated the characteristics of providers of these services in Japan by incorporating technical and institutional complementarity. The main findings are as follows.

(1) Experience services are classified from the viewpoint of complementarity in that crop-wise and operation-wise experience services are defined by technical 
complementarity with tight seasonality while food and rural culture experience services are defined by institutional complementarity with less seasonality.

(2) NGOs and non-profit corporations play a positive role in provision of food and rural culture experiences, which indicates that institutional complementarity of rural life aspects has an affinity with the quasi-public sector. This fact shows that the quasi-public sector will be able to promote the educational function in agriculture throughout a wider area because of the range of their networking capability than could be achieved within the range of original institutional complementarity, which was limited to farm households and rural community.

(3) Common issues that need improvement are Internet availability, charging for services and training programs aimed to help providers offer better service quality. Partnership with NGO and non-profit corporations and the public sector will be effective in easing the constraints of seasonality and increase services that can be accompanied by an overnight stay.

(4) Consequently, it is important to recognize the significance of institutional complementarity because it will widen our perspective for farm diversification and the promotion of the educational function. Further study is necessary on the relationship between cultural aspects and farm diversification.

\section{References}

[1] Hagedorn, K., Rethinking the Theory of Agricultural Change in an Institution of Sustainability Perspective, G. Van Huylenbroeck, W. Verbeke, L. Lauwers, I. Vanslembrouck, and M. D'Haese (eds.) Importance of Policies and Institutions for Agriculture, Academia Press: Gent, pp.33-56, 2003.

[2] OECD, Multifunctionality: Towards an Analytical Framework, OECD: Paris, 2001.

[3] OECD, Multifunctionality: The Policy Implications, OECD: Paris, 2003.

[4] Ohe, Y., On the Relationship between Multifunctionality and Hamlet Activities as a Rural Institution, Jpn. J. Rural Econ. Vol.8, pp.41-57, 2006.

[5] Ohe, Y., Evaluating Jointness of Multifunctional Agriculture: the Educational Function of Dairy Farming in Japan, Aravossis, K., C. A. Brebbia, E. Kakaras, and A. G. Kungolos (eds.) Environmental Economics and Investment Assessment, WIT Press: Southampton, pp.337-346, 2006.

[6] Japan Science Council, Evaluating Multifunctionality in Agriculture and Forestry, Connecting Global Environment and Human Life (Report), p.16, 2001 . 